\title{
Fastener products lightweight design and forming process simulation
}

\author{
Jinn-Jong Sheu*, Chien-Jen Ho, Cheng-Hsien Yu, and Kuo-Ting Wu \\ Department of Mold and Dies Engineering, National Kaohsiung University of Science and \\ Technology, No. 415, Jiangong Road, Sanmin District, Kaohsiung City 80778, Taiwan
}

\begin{abstract}
In this research, an integrated design system was established to design the product of nuts with flange and generate the lightweight geometry of product. The multi-stage forming process was evaluated using the CAE simulations. The topology optimization method was used to achieve the lightweight design, that included keeping necessary geometrical features and remove the excess volumes. The topological discrete model had been remodelled into a meaningful geometry which is able to satisfy the requirement of proof load of fastener specification. The final design of the lightweight geometry was adopted to test the capability of carrying proof load required using CAE simulations with the boundary conditions of the related ASTM standard. In the evaluation stage, the finite element method was used to do the topology optimization, the proof load evaluation, the forging process and the die stress analysis. The simulation results showed the lightweight design was able to reduce the weight of product and maintain enough mechanical strength. The proposed process and die designs were able to obtain the lightweight product without defects.
\end{abstract}

\section{Introduction}

The light weight design is the main stream of vehicle components in order to decrease both of the material utilization and the energy consumption. Fasteners are the basic and the most important components to assemble the neighbouring components of a vehicle to hold the car body structures. The light weight design of fasteners is the easiest way to cut the weight of a car without modifying the original component designs. To change the material of fasteners from steel to titanium alloy or high strength aluminium alloy is another option of lightweight design but the higher materials cost was required. New geometry design of fasteners is able to cut the weight of fasteners using the original material and the same forming process.

The new product design takes into consideration of the product strength requirement and the light weight capability. Unseld et al. [1] proposed the product development procedure using the CAE technology to evaluate both of the mechanical strength and the forming process. The results were able to achieve weight reduction up to $25 \%$ and the cost reduction potential up to $10 \%$. Alves et al. [2] proposed the tube nut and screw forming

${ }^{*}$ Corresponding author: jjsheu@nkust.kuas.edu.tw 
process design using the combination of the extrusion, the ironing, and the expanding methods. The hollow types of screws and nuts are very efficient for the lightweight designs. The topology analysis method can cut the unnecessary materials of a component under the specified loading and the boundary conditions. Emmelmann et al. [3] used topology optimization technique to design a lightweight laser-remote-scanner components successfully. Lightweight of structure is crucial to design the dynamically moving system. Yüksel et al. [4] proposed two different contact models of the linear guide of a five-axis milling machine to present the effects of the stiffness of the contact elements. The entire machine assembly depends on the least stiff components of the linear guide. It is crucial to deal of the contact conditions for the topology optimization process. The surface contact model is able to obtain the best results that the stiffness is increased by $20 \%$ and the structure weight is decreased by $10 \%$. Goss et al. [5] had studied the high strength fastener cold forging process with the work hardening materials using the flownets analysis of the $\mathrm{CAE}$ and the experimental results, respectively. The benefit of using work hardening material is the saving of heat treatment, yet the forging process is more difficult and the tool life may be poor.

The testing methods of the fasteners for different conditions are proposed to mimic the real applications. Andrew et al. [6] proposed a new testing method to evaluate the failure of the high strength nut made from nickel-base super alloy which is used on the A-10 aircraft. A combination of shanking and pre-load and push the nuts to extreme limits was tested to evaluate the subpar capability. The proposed testing method is able to provide quantitative data to evaluate the impact of the manufacturing process on the performance of the bolt and nut combination. Hagiwara et al. [7] developed a fastener testing machine in accordance with the ISO 16047 torque / clamp force testing standard. The strain gauges of the force and the torque measurement are designed to test the clamp force and the torque applied on the testing bolt. Izumi et al. [8] studied the tightening and loosing mechanism of the fasteners using the FEM method. The shear stress of the threaded fastener predicted with the conventional mechanics is over estimated. The tightened torque is lower than the prediction and results in the loose of fastener earlier than the expectation period. While the FEM results are in good agreement with the experiment tests. The sliding phenomena of the contact face indicated the loosing condition is occurred. Castelluccio et al. [9] adopted FEM simulation to study influences of the geometry, the material, and the friction on the load-displacement of a fastener. A three-dimensional model is capable of describing the load-displacement of the elastic and the plastic deformation of the threaded fastener. ASTM-F606/F606M-16[10] are the standard mechanical strength testing methods for the threaded bolt and nut. This paper also used this standard to evaluate the mechanical capability of the designed fastener.

The demonstrated product of lightweight fastener is a hexagonal nut with flange. The geometry of the fastener was obtained using the topology optimization to obtain the feasible lightweight geometry patterns. Design of Experiment (DOE) method was adopted to obtain the exact geometry parameters of the fastener. CAE simulations were performed to evaluate the performance of the lightweight design. The proposed design flow of a lightweight fastener was shown in Fig. 1.

\section{Material and geometry of the high strength fastener}

The high strength fastener property class (P.C.) 9.8 M6 nut was adopted for the demonstration of the lightweight design. The material of the nut is 10B21 and the main dimensions of the nut were designed according to the ISO/DIS 4161 standard [11]. The dimensions of nut and the flow stress model of the material were shown were shown in Fig. $2 \mathrm{a}$ and Fig. $2 \mathrm{~b}$, respectively. The flow stress of 10B21 was obtained by cylinder upsetting 
experiment at strain rate 0.1 , room temperature $\left(20^{\circ} \mathrm{C}\right)$. The volume of the nut is $470.77 \mathrm{~mm}^{3}$.

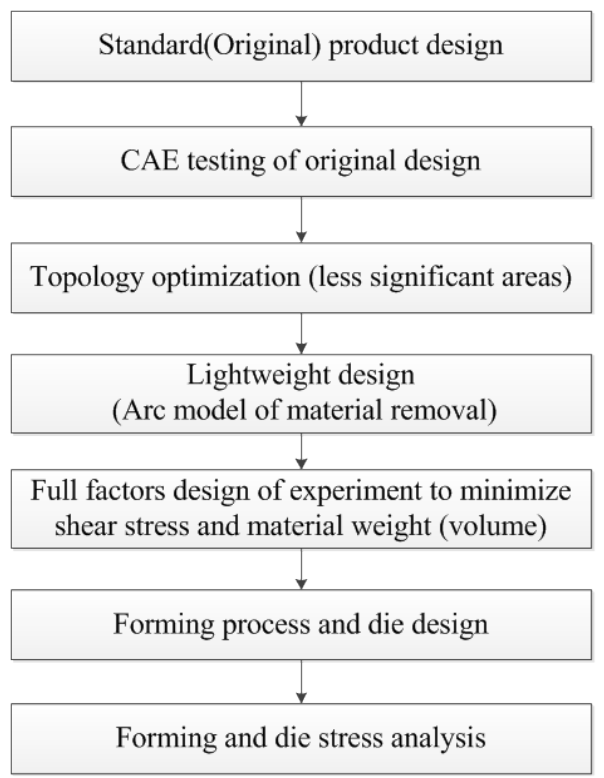

Fig. 1 Flowchart of the lightweight design of fastener.

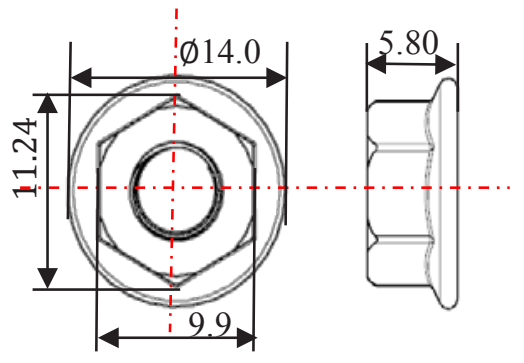

(a) Dimensions and geometry

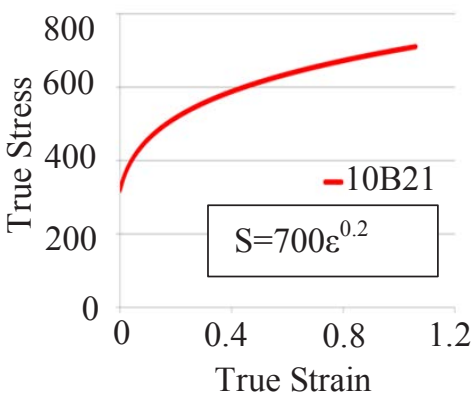

(b) Flow stress curve

Fig. 2 (a) Dimensions of the fastener and (b)the flow stress of billet material.

The mechanical property testing method of the designed fastener was in accordance with the ASTM standard [10]. The CAE model for the proof load test was shown in Fig. 3. The material model of the workpiece was assumed to be plastic and presented using power law model. The mandrel and the bottom die were assumed to be rigid. The billet was modelled using 126,738 tetrahedral volume meshes and 25,822 nodes with the minimum mesh size of $0.125 \mathrm{~mm}$. The meshes outer area of the billet were refined with the density ratio 0.1 (one-tenth of the original meshes). The mandrel was moved downwardly with the velocity of $25 \mathrm{~mm} / \mathrm{min}$. The Columb friction coefficient was set to 0.07 for steel die. The stroke of the mandrel was stopped while the poof load of nut reaching the limit value $13,100 \mathrm{~N}[12]$. 


\section{Topology optimization and DOE lightweight design optimization}

Topology optimization was carried out to find the less significant areas to cut the materials of the lightweight design. The quantative amounts of the removed materials were determined using the DOE optimization. The CAE model of the mechanical testing, the topology optimization of the material removal, and the suggested geometrical parameters for DOE optimzation were shown in Fig. 4. The topology optimzation results had revealed the areas of the removable materials were distributed on the top and the side faces of the nut. A half arc model defined by the radius $R$ and the center distance $L$ with respect to the nut center was proposed to cut the material at the less significant areas of the topology analysis results. The design factors $R$ and $L$ were normalized, the radius of the arc was divided by the side length of nut $L_{\text {side, }}$, and the arc center was divided by the parallel side distance $L_{\text {parallel }}$, to obtain better DOE results. The design factors and the levels of factor were shown in Table 1.
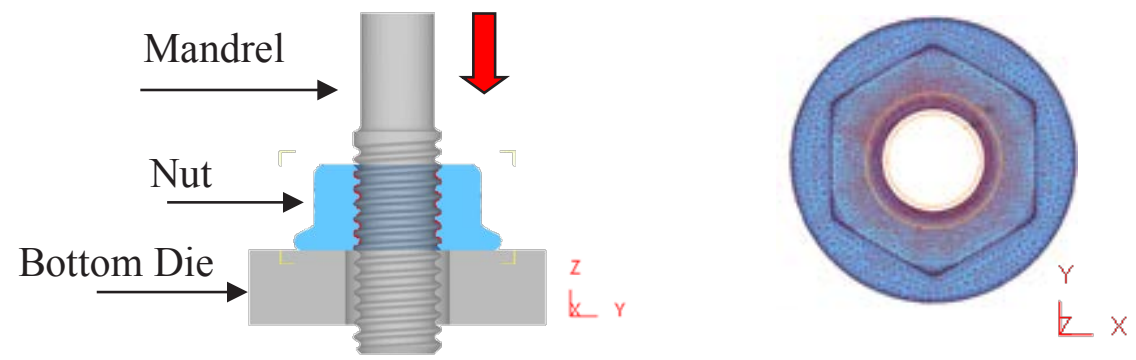

Fig. 3 Testing method and the CAE model of the designed nut.

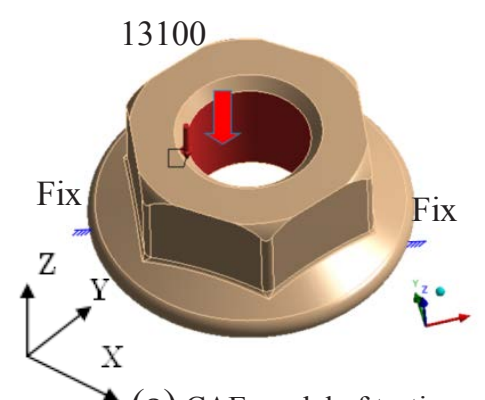

(a) CAE model of testing

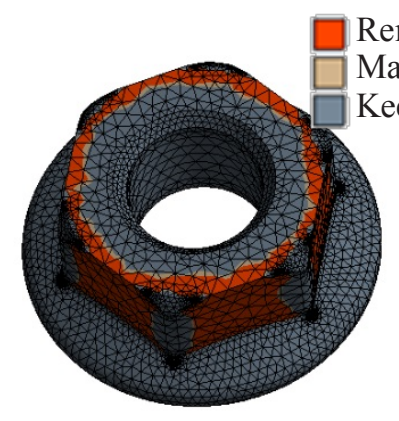

(b) Topology optimzation

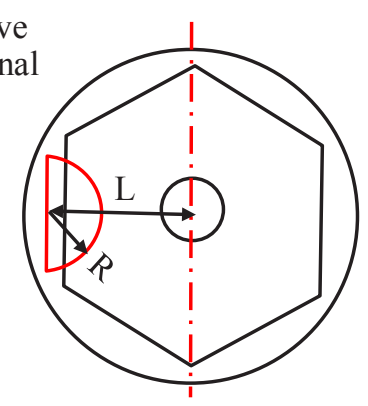

(c) Parameters for DOE

Fig. 4 Topology analysis model and Parameter Definition.

The goal of the DOE optimization is to minimize both of the maximum shear stress in the Z-R direction $\left(\tau_{z r}\right)$ and the Volume $(\mathrm{V})$ of remained materials. The weight facotrs of $60 \%$ and $40 \%$ were proposed to calculate the cost function of the $\mathrm{i}^{\text {th }}$ case $\left(C F_{i}\right)$ of DOE in Eq. 1 considering the effects of the stress with more sigificance and the volume with less significance in this paper. Penalty value 1 was given in the case of the maximum shear stress higher than the allowance of shear $160 \mathrm{Mpa}$ of the nut material to prevent the designs of product wihtout enough mechanical strength. The signal to noise ratio $(\mathrm{S} / \mathrm{N})$ for $n$ times repeated tests with corresponding results $y_{i}$ of the smaller-the-better optimization is shown in Eq. 2. 
Table 1. Design factors and corresponding levels.

\begin{tabular}{|c|c|c|c|}
\hline Factors & 1 & 2 & 3 \\
\hline $\mathrm{L} / \mathrm{L}_{\text {parallel }}$ & 1 & 1.1 & 1.2 \\
\hline $\mathrm{R} / \mathrm{L}_{\text {side }}$ & 0.8 & 1 & 1.2 \\
\hline
\end{tabular}

$C F_{\mathrm{i}}=\left(\frac{\tau_{i}-\tau_{\min }}{\tau_{\max }-\tau_{\min }} * 0.6+\frac{V_{i}-V_{\min }}{V_{\max }-V_{\min }} * 0.4\right)+$ Penalty value

$S / N=-10 \log \left(\frac{1}{n} \sum_{i=1}^{n} y_{i}^{2}\right)$

\section{Forming process and die design}

The proposed forming operation processs including the billet cutting (OP1), the heading (OP2), the upsetting (OP3), the hexagonal forging (OP4), the flange forming (OP5), and the finishing (OP6) operations. The selected billet size was $9 \mathrm{~mm}$ in diameter and $6.95 \mathrm{~mm}$ in height according to the required product volume $\left(442.28 \mathrm{~mm}^{3}\right)$ of lightweight design. The forming process and the corresponding die designs were shown in Fig. 5 for the production of the optimal designed fastener.

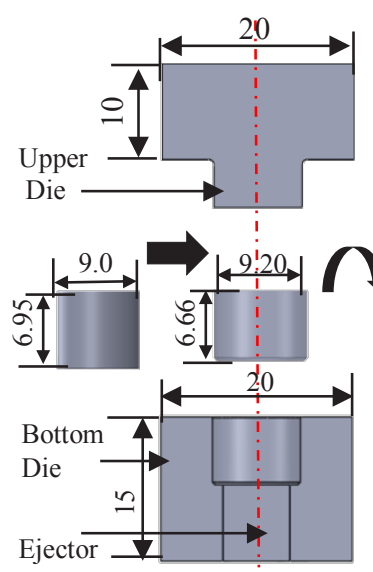

Z

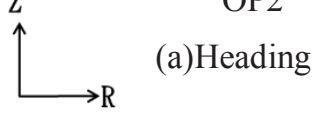

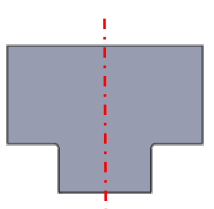
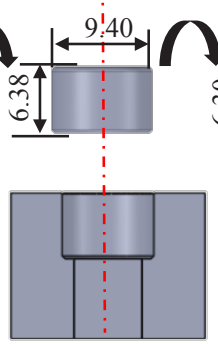

OP3
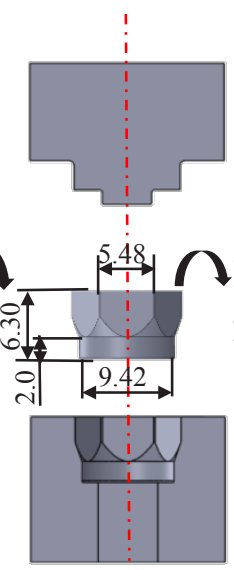

OP4

(b)Upsetting

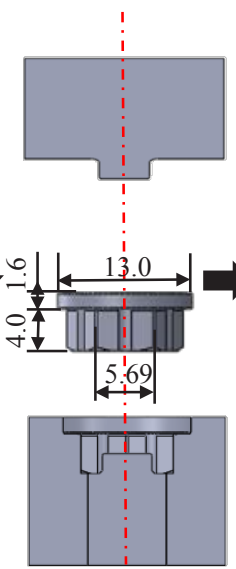

OP5

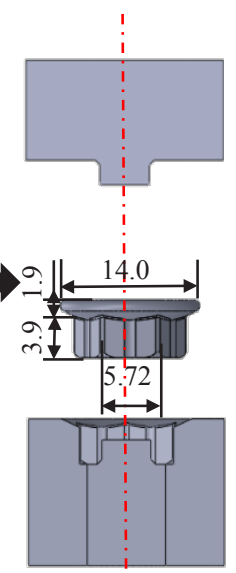

OP6
(c)Hexagonal Forging
(d)Flange forming

(e)Finishing

Fig. 4 Forming process and die design for nut forging.

\section{Forming process and die stress analysis}

The CAE models of the forming process and the die stress analyses were shown in Fig. 6. The billet material is boron steel 10B21 with the Young's module $210 \mathrm{GPa}$, Poisson ratio 0.3 , yielding stress $320 \mathrm{MPa}$, tensile strength $510 \mathrm{MPa}$, and elongation $15 \%-30 \%$. For the forming process analysis, the tools were assumed to be rigid. The billet was modelled with tetrahedral volume mesh using minimum size $0.131 \mathrm{~mm}$ as shown in Fig. 6 (a). The toolbillet friction was modelled using the constant shear friction factor of 0.12 . For die stress analysis, all of the tools were meshed and assumed to be elastic. The top surface of punch 
and the bottom surface of the die were assumed to be fixed, the die surface loads were mapped from the forming process simulation results. The CAE models and the boundary conditions of the die stress analysis for finishing forming were shown in Fig. 6(b) and Fig. 6(c). The die material adopted was Tungstun carbide (WC) with the Young's module 650 $\mathrm{GPa}$, Poisson ratio 0.24 , compressive strength $3130 \mathrm{MPa}$, and tensile strength $1660 \mathrm{MPa}$.

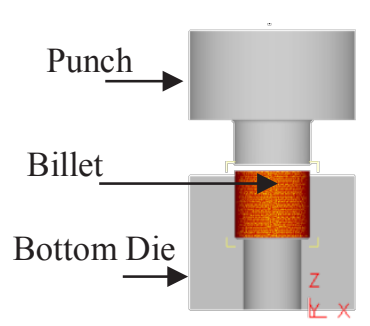

(a) Forming model

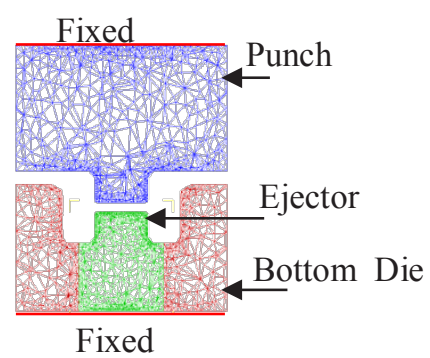

(b)Die stress analysis

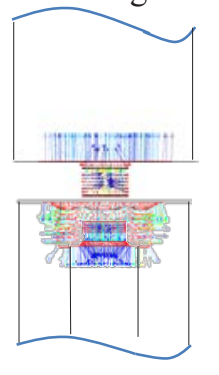

(c) Contact forces mapping
Force $(\mathrm{N})$

758

505

253

Fig. 5 CAE modellings of forming and die stress analyses.

\section{Results and discussions}

\subsection{Mechanical Strength analysis of lightweight designs}

The full factor DOE design layout and the mechanical testing analysis results were shown in Table 2. The response chart of the analysis results was shown in Fig.7(a) which gives the optimum combination of the normalized center distance $\left(\mathrm{L} / \mathrm{L}_{\text {parallel }}\right)$ and the normalized radius $\left(\mathrm{R} / \mathrm{L}_{\text {side }}\right)$ of the lightweight cutting arc were 1.2 and 0.8 , respectively. The optimum lightweight design of the product was shown in Fig.7(b) which showed the product volume is $442.28 \mathrm{~mm}^{3}$ and achieved $6.05 \%$ weight reduction in comparison with the original product design (volume $470.77 \mathrm{~mm}^{3}$ ).

The mechanical strength of the origianl and the lightweight designs were evaluated uisng the proposed strength testing simulaiton method. The smaller of the maximum shear stress in the ZR-direction is the better deisgn. The maximum shear stress in the ZRdirection of the standard and the lightweight designs shown in Fig. 8 were $128 \mathrm{MPa}$ and $131 \mathrm{MPa}$, respectively. Both of the maximum shear stress of these two designs are lower than the allowance of shear stress $(160 \mathrm{MPa})$. That means both of the product designs were qualified.

Table 2. Trial runs of the full factor DOE and theanalysis data.

\begin{tabular}{|c|c|c|c|c|c|c|c|}
\hline Trials & $\begin{array}{c}\mathrm{L} / \\
\mathrm{L}_{\text {parallel }}\end{array}$ & $\begin{array}{c}\mathrm{R} / \\
\mathrm{L}_{\text {side }}\end{array}$ & $\tau_{z r}$ & Volume $\left(\mathrm{mm}^{3}\right)$ & $\begin{array}{c}\text { Light } \\
\text { weight } \\
(\%)\end{array}$ & $\mathrm{CF}$ & $\mathrm{S} / \mathrm{N}$ \\
\hline 1 & 1 & 0.8 & 151 & 401.13 & 14.79 & 0.524 & 5.613 \\
\hline 2 & 1 & 1 & 166 & 377.09 & 19.9 & 1.646 & -4.329 \\
\hline 3 & 1 & 1.2 & 171 & 348.96 & 25.87 & 1.6 & -4.082 \\
\hline 4 & 1.1 & 0.8 & 139 & 424.02 & 9.93 & 0.442 & 7.092 \\
\hline 5 & 1.1 & 1 & 147 & 405.47 & 13.87 & 0.482 & 6.339 \\
\hline 6 & 1.1 & 1.2 & 155 & 381.72 & 18.92 & 0.5 & 6.021 \\
\hline 7 & 1.2 & 0.8 & 131 & 442.28 & 6.05 & 0.4 & 7.959 \\
\hline 8 & 1.2 & 1 & 136 & 431.11 & 8.42 & 0.427 & 7.391 \\
\hline 9 & 1.2 & 1.2 & 143 & 413.72 & 12.12 & 0.458 & 6.783 \\
\hline
\end{tabular}




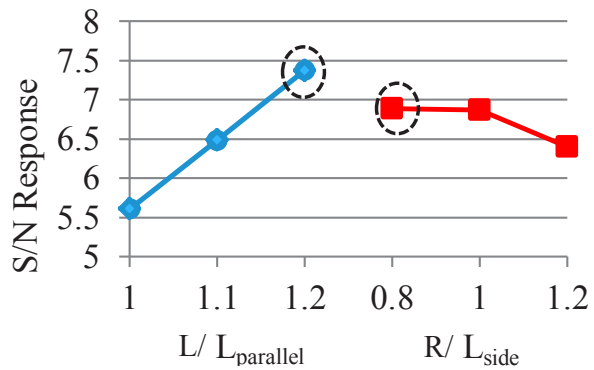

(a) $\mathrm{S} / \mathrm{N}$ Response graph
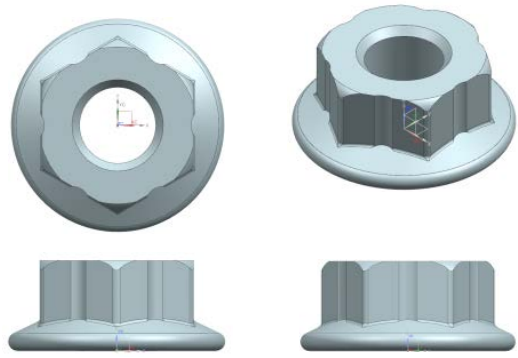

(b) Lightweight nut

Fig. 7 S/N Response graph and the corresponding optimum geometry desing of nut.

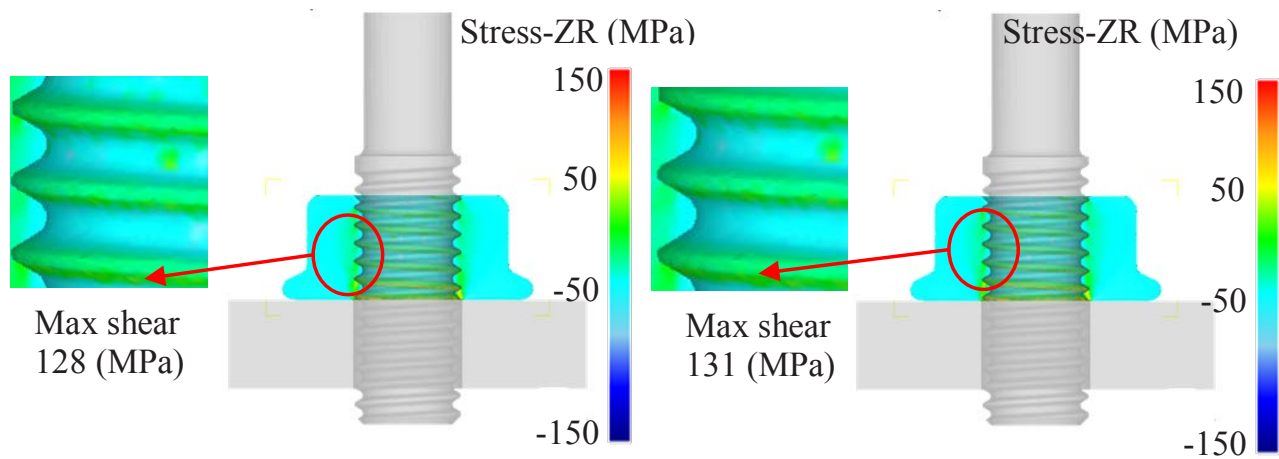

(a) Shear stress of standard design

(b) Shear stress of lightweight design

Fig. 8 Mechanical strength testing results of the original(left) and the lightweight design(right).

\subsection{Forminmg process simulation}

The froming process simulation was carried out to verify the feasibility of manufacturing and the final property class of the product. The main dimesions of the forged prat were shown in Fig. 9(a). Dimensions of the flange diameter, 3.98, the parallel side distance, 9.87, and the height, 5.80, were all fullfiilled with the specification of the tolerance. The maximum effective stress of the product was higher than $880 \mathrm{MPa}$ as shown in Fig. 9(b). The simulation results had shown the mechanical strength was increased and fullfill with the property class 9.8 requiremnt of the ISO 898-1:2013 standard (Ys:720MPa, Ts:900MPa).

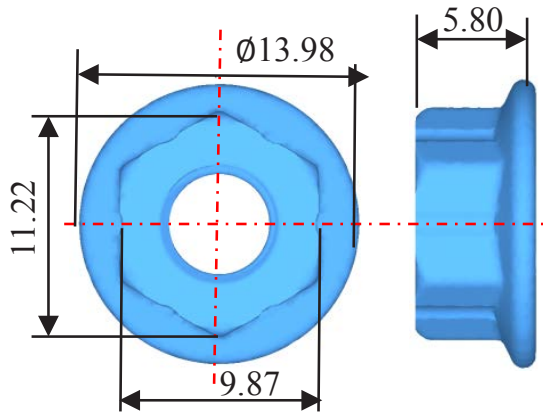

(a) Geometry of product

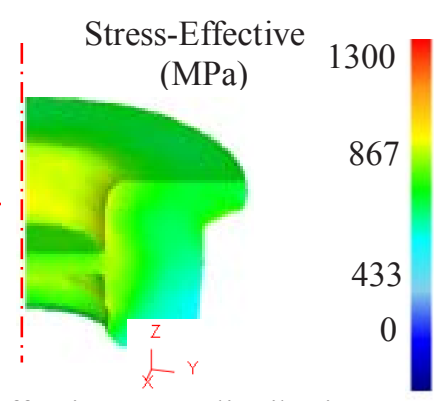

(b) Effective stress distribution 
Fig. 6 Geometry and effective stress distribution of the lightweight product.

\subsection{Die stress analysis}

Distributions of the die stress in the circumferential (theta)direction for the forming operations 2 to 6 were shown in Fig. 10. The die srtresses in operations 5 and 6 are too high for the die material. It shows the one-piece die design for operation 5 and 6 is not feassible. Split die insert and the compressive ring designs are required tot solve the die failure problem.

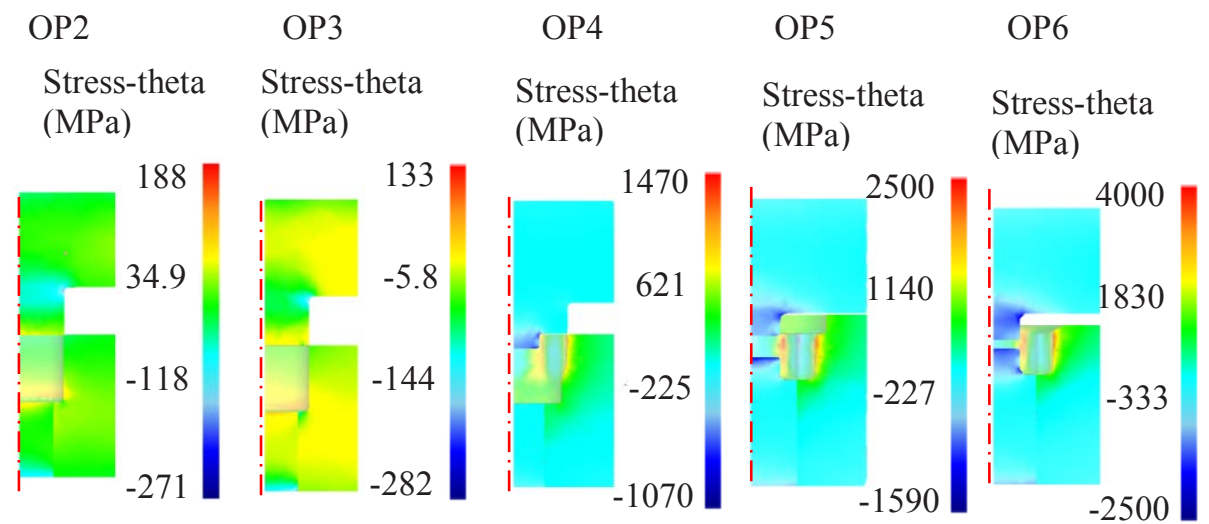

Fig. 7 Die stress distribution in the circumferential (theta) direction for the nut forming process.

\section{Summary}

This paper presented the lightweight design method via CAE simulations of the mechanical property testing, forming process simulation, and the die stress analysis. The results of this study showed

(1) The CAE technologies are capable of creating lightweight design feasibly.

(2) Integration of the topology optimization and theDOE technique is possible to design the lightweight products with qualified mechanical property.

(3) The high stress of dies had revealed the one-piece die design is not feasible for mass production of nuts. The compressing ring designs were required to protect the die insert and give enough die life for the massive production of nut.

\section{References}

1. P. Unseld, L. Kertesz, S. Hasler, ICFC (2015)

2. L.M.Alves, C.M.A.Silva, P.A.F.Martins, J CLEAN PROD, 135, 1673-1680 (2016)

3. C.Emmelmann, M.Kirchhoff, F.Beckmann, Phys Procedia,12, 459-464 (2011)

4. E.Yüksel, E.Budak, A. S.Ertürk, Procedia CIRP, 58, 487-492 (2017)

5. D.C. Goss, J MATER PROCESS TECH, 98, 135-142 (2000)

6. D.L. Andrew, S.S. Carlson, J. H. Macha, R. T. Pilarczyk, ENG FAIL ANAL, 74, 35-53 (2017)

7. M. Hagiwara, Y. Mano, M. Hamada, K. Nunogami, H. Ozeki, S. Ito , 7, J ADV MECH DES SYST, 3, 324-332 (2009)

8. S. Izumi, T. Yokoyama, A.Iwasaki, S. Sakai, ENG FAIL ANAL, 12, 604-615 (2005)

9. G.M.Castelluccio, M.R.W.Brake, Comput Struct, 186, 1-10(2017)

10. ASTM-F606/F606M-16, (2016) 
11. ISO 4161, (2012)

12. ISO 898-1, (2013) 